\title{
Quiste epidermoide testicular. Diagnóstico ecográfico preoperatorio y correlación radiopatológica
}

\author{
Dres. Erick Santa Eulalia $M{ }^{*(1)}$, Pedro José Sánchez $S^{(2)}$, Ana Margot Jara $D^{(1)}$, Fernando Ernesto Trucco(1), \\ Florin Olimpiu Lenghel(2). \\ * Departamento de Radiodiagnóstico, Hospital Obispo Polanco. Teruel, España. \\ 1. Médico residente de Radiodiagnóstico. Departamento de Radiodiagnóstico, Hospital Obispo Polanco. Teruel, España. \\ 2. Médico especialista adjunto de Radiodiagnóstico. Departamento de Radiodiagnóstico, Hospital Obispo Polanco. Teruel, España.
}

\section{Testicular epidermoid cyst. Preoperative ultrasound diagnosis and radiopathological correlation}

\begin{abstract}
The low incidence of testicular epidermoid cyst (1-2\% of all testicular tumors), makes ultrasound findings the key to making, or at least suggesting, a precise preoperative diagnosis, thus making a conservative treatment possible.

We present two cases with ultrasound diagnosis of epidermoid cyst, confirmed later after surgery. We review the literature, emphasizing the evaluation of the ultrasound images and their correlation with the anatomopathological findings.
\end{abstract}

Keywords: Testicular epidermoid cyst, Testicular tumor, Ultrasound.

Resumen: La escasa incidencia del quiste epidermoide de testículo (1-2\% de todos los tumores testiculares), hace de los hallazgos ecográficos la clave para realizar o al menos sugerir un diagnóstico prequirúrgico preciso, haciendo por tanto posible un tratamiento conservador.

Presentamos dos casos con diagnóstico ecográfico de quiste epidermoide, confirmado posteriormente tras cirugía. Realizamos una revisión de la bibliografía, enfatizando en la valoración de las imágenes ecográficas y su correlación con los hallazgos anatomopatológicos.

Palabras clave: Ecografía, Quiste epidermoide testicular, Tumor testicular.

Santa Eulalia E, Sánchez PJ, Jara AM, Trucco FE, Olimpiu F. Quiste epidermoide testicular. Diagnóstico ecográfico preoperatorio y correlación radiopatológica. Rev Chil Radiol 2015; 21(2): 49-52.

Correspondencia: Dr. Erick Santa Eulalia M. / elesfenoides@gmail.com

Trabajo recibido el 09 de noviembre de 2014. Aceptado para publicación el 06 de julio de 2015.

\section{Introducción}

El 95\% de las masas intratesticulares son de naturaleza maligna, por lo que toda masa intratesticular será considerada maligna hasta que no se demuestre lo contrario y se tratará, por lo tanto, mediante orquiectomía radical(1-4).

Los tumores malignos testiculares representan la neoplasia más prevalente en los varones entre los 15 y 35 años de edad. La evaluación de estos tumores incluye historia clínica, examen físico, marcadores tumorales y estudios de imagen escrotal como la resonancia magnética o la ecografía. Esta última presenta una sensibilidad cercana al $100 \%$ para detectar lesiones intratesticulares, por lo que en la actualidad sigue siendo el método de elección inicial para el estudio de la patología intraescrotal ${ }^{(5)}$.
El quiste epidermoide testicular es un tumor benigno raro que representa aproximadamente el 1-2\% de las neoplasias intratesticulares y suele presentar patrones ecográficos característicos ${ }^{(1-7)}$.

Presentamos dos casos diagnosticados en nuestro hospital mediante ecografía preoperatoria y realizamos una revisión de la literatura actualizada sobre el tema.

\section{Presentación de los casos Caso 1}

Paciente varón de 21 años que desde hace más de un año nota un bulto, no doloroso en el testículo derecho. A la exploración física nódulo de consistencia dura en el polo inferior del testículo derecho. Exámenes de laboratorio sin alteraciones, con valores 
de alfafetoproteína y beta-HCG normales.

Ecografía escrotal: masa intratesticular de morfología redondeada y $18 \mathrm{~mm}$ de diámetro, en el polo inferior del testículo derecho. Bien delimitada, hipoecógena, presenta múltiples finas láminas internas hiperecógenas, de disposición concéntrica anular, y ausencia de flujo al Doppler, estableciéndose el diagnóstico ecográfico de quiste epidermoide testicular (Figura 1).

Se realizó orquiectomía derecha y colocación de prótesis con posterior diagnóstico anatomopatológico de teratoma maduro monodermal (quiste epidérmico) (Figura 2).

\section{Caso 2}

Paciente varón de 26 años de edad sin antecedentes de interés con sensación de bulto no doloroso en testículo derecho de pocos meses de evolución. A la exploración física se encuentra nódulo de consistencia dura en el polo inferior del testículo derecho. Marcadores tumorales sin alteraciones.
Ecografía escrotal: nódulo redondo bien definido de $11 \mathrm{~mm}$ en localización periférica del polo inferior del testículo derecho. La lesión no presenta vascularización con técnica Doppler color y muestra una calcificación lineal periférica así como ecoestructura interna heterogénea de menor ecogenicidad que el parénquima testicular adyacente, con finas líneas hiperecógenas dispuestas "en capas de cebolla", compatible con quiste epidermoide testicular (Figura 3).

Se realizó tumorectomía con biopsia intraoperatoria y posterior diagnóstico anatomopatológico de quiste epidermoide testicular: lesión quística con presencia de escamas córneas y queratina (Figura 4).

\section{Discusión}

Aunque raro (1-2\% de todas las masas intratesticulares), el quiste epidermoide es el tumor testicular benigno intratesticular más frecuentemente encontrado. Generalmente se presenta entre la segunda y cuarta décadas de vida, aunque pueden aparecer a cualquier edad y predomina en la raza blanca ${ }^{(1,6)}$.

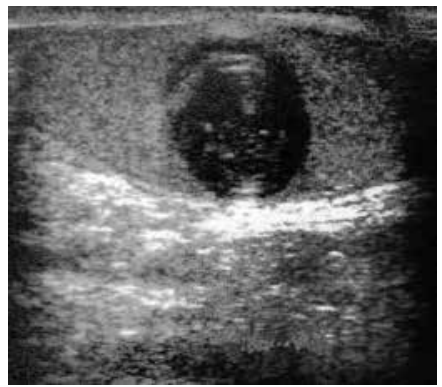

Figura 1. Ecografía testicular.
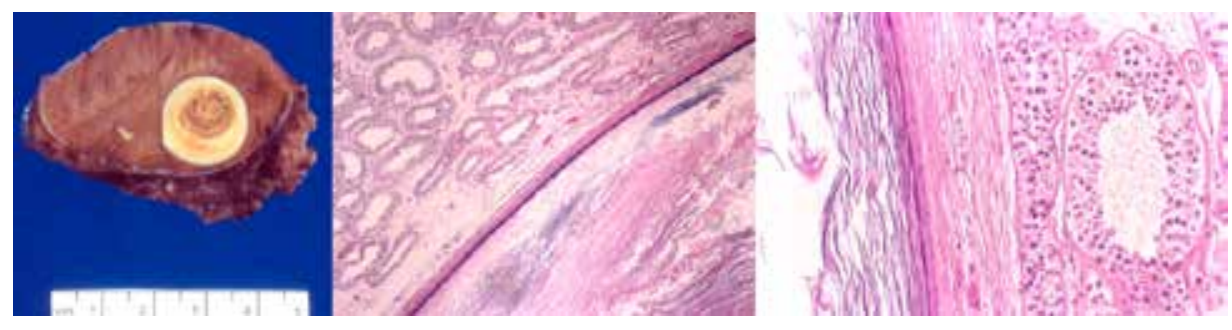

Figura 2. Pieza anatómica testículo derecho, estudio histológico de quiste epidérmico.

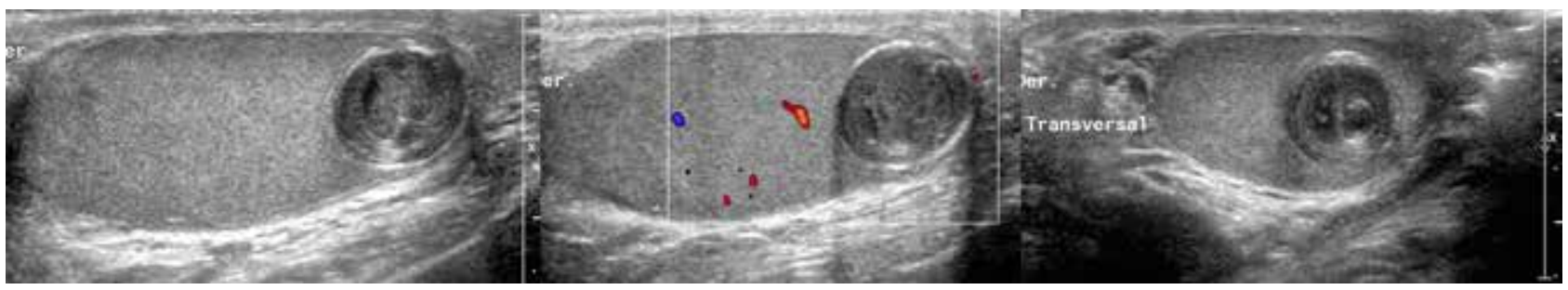

Figura 3. Ecografía testicular con finas líneas hiperecógenas dispuestas "en capas de cebolla",

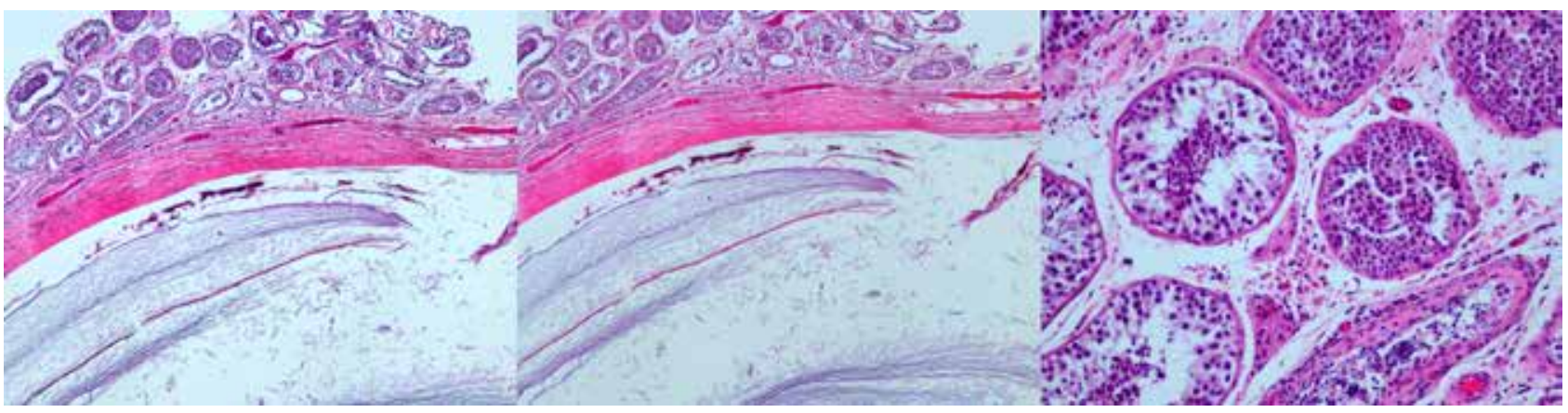

Figura 4. Biopsia de quiste epidermoide testicular: Lesión quística con presencia de escamas córneas y queratina. 
Suele presentarse como una tumoración solitaria no dolorosa de consistencia firme, morfología redondeada u oval, bien circunscrita, con diámetro medio de $2 \mathrm{~cm}(1-3 \mathrm{~cm})$ y marcadores tumorales negativos ${ }^{(7)}$.

Existen varias teorías de la histogénesis del tumor, pero la mayoría de autores sugiere que el quiste epidermoide testicular constituye el desarrollo de un teratoma, con crecimiento exclusivo de la capa ectodérmica (teratoma monodérmico). Otra teoría propuesta es que se trate de una metaplasia escamosa del epitelio de los túbulos seminíferos o rete testis ${ }^{(7,12,15)}$.

Los criterios histológicos para el diagnóstico de esta lesión siguen siendo, al día de hoy, los descritos por Price ${ }^{(16)}$ en 1969:

1. Localización intraparenquimatosa y naturaleza quística.

2. Contenido queratinoso en la luz.

3. Pared compuesta por tejido fibroso, con una capa de epitelio lineal escamoso, completa o incompleta, rodeado por parénquima testicular que puede ser atrófico.

4. Ausencia de otros elementos teratomatosos o elementos dérmicos anexiales (glándulas sebáceas o folículos pilosos) en el quiste o en el parénquima testicular.

5. Ausencia de cicatriz en el parénquima testicular.

En la pieza macroscópica se suele encontrar una lesión redondeada pequeña $(1-3 \mathrm{~cm})$ de color amarillo nacarado, con una cápsula fibrosa que puede presentar calcificaciones en grado variable. Su contenido puede variar en consistencia desde totalmente líquido hasta grumoso. Microscópicamente la pared fibrosa está tapizada parcial o completamente por epitelio epitelial escamoso y el contenido consiste en detritos de epitelio descamado y queratina en grado variable $e^{(5,7,13,14)}$.

La apariencia ecográfica es variable, según el grado de maduración y de la cantidad y lo compacto de la queratina en su interior ${ }^{(5,13)}$. Se muestran como nódulos intratesticulares redondos $u$ ovales muy bien delimitados del tejido testicular circundante, avasculares con técnica Doppler color. En caso de usar contraste ecográfico estas lesiones no presentan realce vascular y con técnica de elastografía ecográfica presentan dureza tisular relativa, respecto al tejido parenquimatoso circundante ${ }^{(8)}$.

Se reconocen cuatro patrones ecográficos del quiste epidermoide testicular ${ }^{(7,13,15,18)}$ :

1. Lesión nodular bien circunscrita, con una cubierta hiperecogénica (correspondiente a la capa fibrosa) y sucesivos anillos concéntricos alternantes, completos o no, de hipo e hiperecogenicidad que le confieren un aspecto característico a la lesión de "capas de cebolla". Los anillos de hiperecogenicidad corresponden histológicamente a zonas de queratina mientras los de hipoecogenicidad a detritos epiteliales. En este mismo patrón puede adquirir una apariencia en "diana" u "ojo de buey": halo hipoecógeno y centro hiperecogénico (queratina).

2. Lesión intensamente calcificada, sin componente quístico.

3. Lesión quística bien definida, con calcificación variable en la cápsula, periférica o central.

4. Lesión con un patrón mixto, de ecogenicidad heterogénea mal definida.

Mediante resonancia magnética estos tumores no presentan realce tras la administración de contraste paramagnético y suelen mostrar dos patrones fundamentales $^{(5-8,13,15,19)}$.

1. Lesión en "diana" presentando, tanto en imágenes potenciadas en T1 como T2, una zona central hipointensa, otra zona intermedia hiperintensa y un anillo periférico hipointenso.

2. Lesión quística que se comporta hipointensa en imágenes potenciadas en T1 e hiperintensa en imágenes potenciadas en T2, generalmente rodeadas de un halo hipointenso en imágenes potenciadas en T1 y T2 que representaría la cápsula fibrosa calcificada.

En la actualidad se recomienda tumorectomía con biopsia intraoperatoria por congelación (incluyendo el tejido parenquimatoso adyacente) en aquellos pacientes que presenten una lesión focal intratesticular menor de $2 \mathrm{~cm}$, con marcadores tumorales negativos y características típicas en imágenes (ecografía o resonancia magnética). De confirmarse que se trata de un quiste epidermoide se da por finalizada la cirugía, de no ser así se realizará orquiectomía radical(6,20).

\section{Conclusiones}

El quiste epidermoide testicular es una lesión focal testicular benigna rara que presenta características ecográficas y por resonancia magnética típicas aunque no patognomónicas, lo que permite al radiólogo sugerir con una alta probabilidad de concordancia el diagnóstico del mismo.

En el contexto clínico y de laboratorio adecuado, estas características típicas de presentación en pruebas de imagen pueden evitar una orquiectomía innecesaria, permitiendo el uso de técnicas quirúrgicas conservadoras, con biopsia intraoperatoria para confirmar la sospecha diagnóstica, como ocurrió en el segundo de los casos que presentamos en este artículo.

\section{Bibliografía}

1. Aganovic L, Cassidy F. Imaging of the scrotum. Radiol Clin North Am 2012; 50: 1145-1165.

2. Mirochnik B, Bhargava P, Dighe MK, Kanth Nalini. Ultrasound evaluation of scrotal pathology. Radiol Clin North Am 2012; 50: 317-332.

3. Pearl MS, Hill MC. Ultrasound of the scrotum. Semin Ultrasound CT MR 2007; 28: 225-248. 
4. Appelbaum L, Gaitini D, Dogra VS. Scrotal Ultrasound in adults. Semin Ultrasound CT MR 2013; 34: 257-273.

5. Leal D, Fariña L, Pesqueira D, Mejide F, Quintana JL, Muller C, et al. Quiste epidermoide testicular. Actas Urol Esp 2010; 34(3): 274-277.

6. Dogra VS, Gottlieb RH, Rubens DJ, Liao L. Benign intratesticular cystic lesions: US features. Radiographics 2001; 21: S273-S281.

7. Loya AG, Said JW, Grant EG. Epidermoid cyst of the testis: radiologic-pathologic correlation. Radiographics 2004; 24: S243-S246.

8. Huang DY, Sidhu PS. Focal testicular lesions: colour Doppler ultrasound, contrast-enhanced ultrasound and tissue elastography as adjuvants to the diagnosis. $\mathrm{Br} \mathrm{J}$ Radiol 2012; 85: S41-S53.

9. Bennett GL, García RA. Benign intratesticular dermoid cyst: Sonographic findings. AJR 2002; 179: 1315-1317.

10. Loberant N, Bhatt S, Messing E, Dogra VS. Bilateral testicular epidermoid cysts. J Clin Imaging Sci 2011; 1: 1-4.

11. Maizlin ZV, Belenky A, Baniel J, Gottlieb P, Sandbank J, Strauss S. Epidermoid cyst and teratoma of the testis: sonographic and histologic similarities. J Ultrasound Med 2005; 24: 1403-1409.

12. Manning MA, Woodward PJ. Testicular epidermoid cysts. Sonographic features with clinicopathologic correlation. J Ultrasound Med 2010; 29(5): 831-837.
13. Rabaza MJ, Medina A, López G, Pardo P. Quiste epidermoide testicular. Radiología 2001; 43(6): 297-299.

14. Kubick-Huch RA, Hamm B. Radiologic-pathologic correlation of the male genital tract. En: Gourtsoyiannis NC, Ros PR editors. Radiolologic-pathologic correlations from head to toe: understanding the manifestations of disease. Berlin, Germany: Springer-Verlag 2005; p. 553-571.

15. Cho JH, Chang JC, Park BH, Lee JG, Son CH. Sonographic and MR imaging findings of testicular epidermoid cysts. AJR Am J Roentgenol 2002; 178: 743-748.

16. Park SB, Lee WC, Kim JK, Choi SH, Kang BS, Moon $\mathrm{KH}$, et al. Imaging features of benign solid testicular and paratesticular lesions. Eur Radiol 2011; 21: 2226-2234.

17. Price EB. Epidermoid cyst of the testis. A clinical and pathological analisys of 69 cases from testicular tumor registry. J Urol 1969; 192: 708-713.

18. Atchley JT, Dewbury KC. Ultrasound appearances of testicular epidermoid cysts. Clinic Radiol 2000; 57: 493-502.

19. Talegón Meléndez A, Rueda Vicente J. Patología escrotal. En: del Cura JL, Pedraza S, Gayete A. Radiología esencial. Madrid: Ed Panamericana 2009; p. 663-672.

20. Gupta SK, Golash A, Thomas JA, Cochlin D, Griffiths $D$, Jenkins BJ. Epidermoid cysts of the testis: The case for conservative surgery. Ann R Coll Srug Engl 2000; 82(6): 411-413.

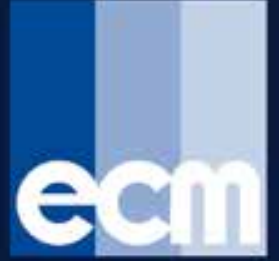

www.ecm.cl

\section{Alpha}

Sistema de ultrasonido compacto, centrado en el valor del diagnóstico real, de rendimiento superior

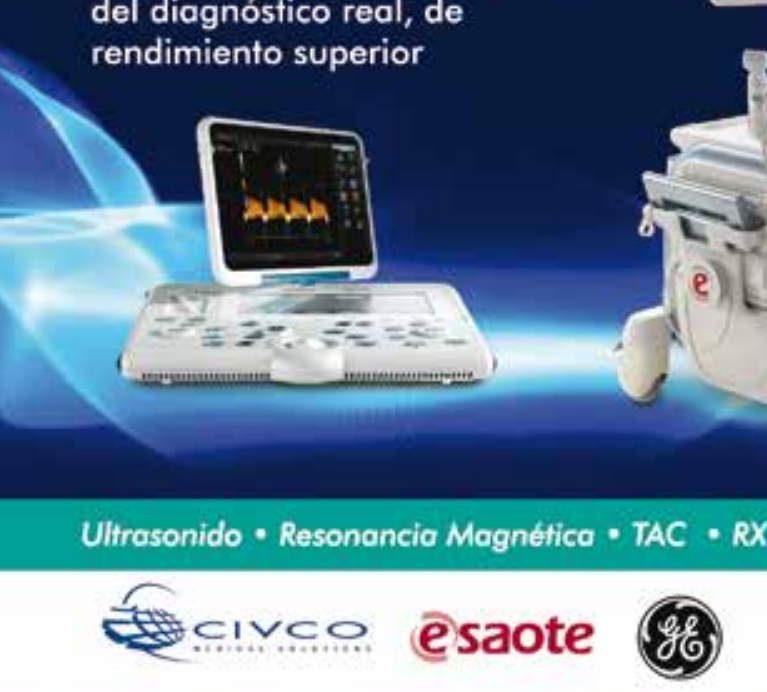
en equipamiento médico, son los Nuevos Representantes de

\section{(e)saote}

